\title{
VISÃO E RELAÇÕES: ELEMENTOS PARA UM METAMODELO EMPREENDEDOR
}

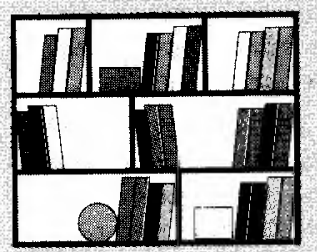

REVISITADA

*Louis Jacques Filion

A “visão" projetada sobre o futuro de seus negócios é o fator principal de sucesso de empreendedores bem-sucedidos.

The main factor of success for entrepreneurs is the capacity of projecting a view of their businesses on the future.

\section{INTRODUÇÃO}

Os modelos estratégicos usados no treinamento de empreendedores, na maioria dos casos, têm sua origem naqueles inicialmente desenvolvidos para as grandes empresas. Entretanto, eles contêm fatores que não parecem tão importantes no processo do pensamento estratégico do pequeno empreendedor, como a análise dos ambientes interno e externo à sua empresa, a competição e as previsões para o desenvolvimento do setor in-

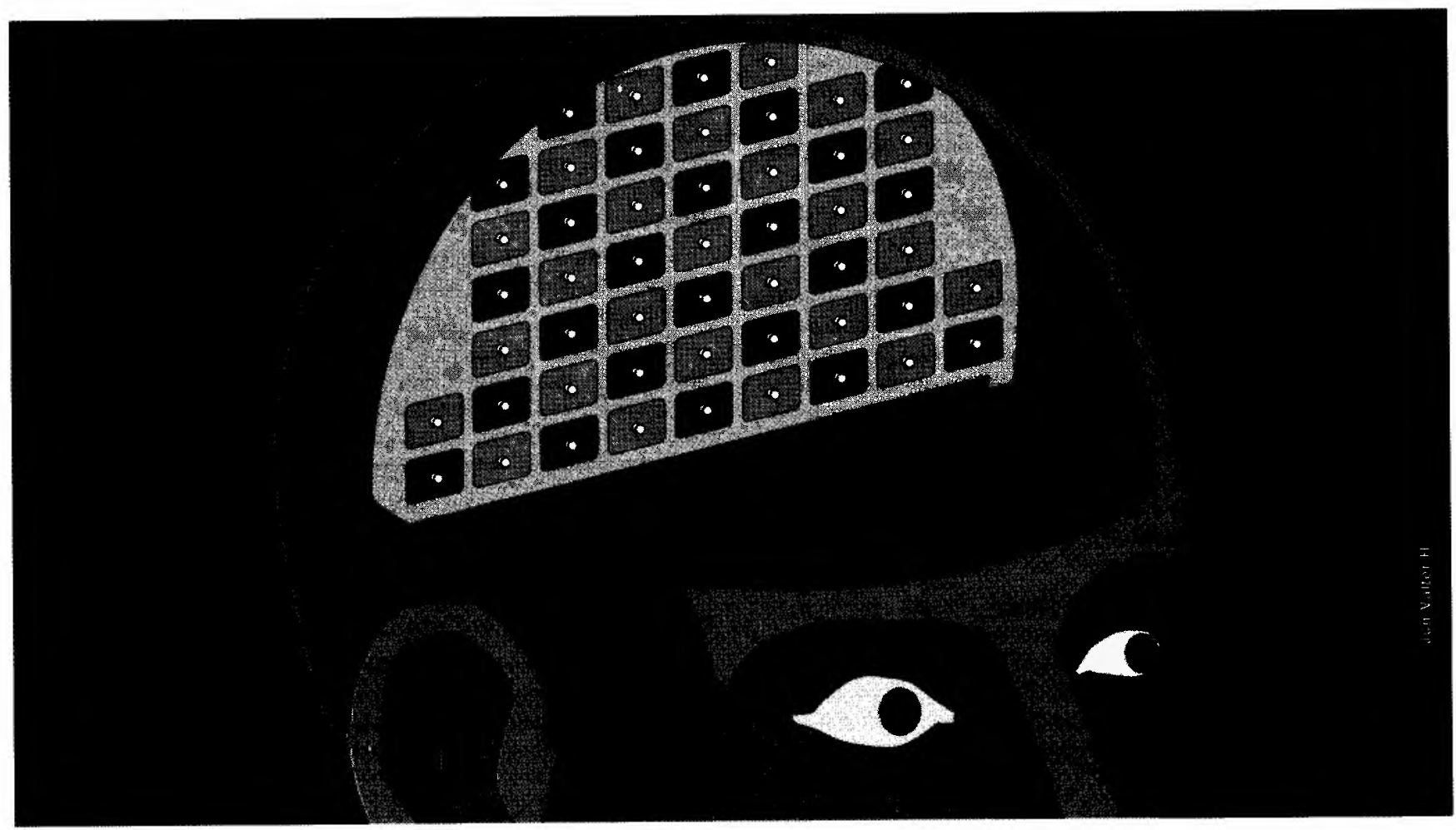

* Professor do Service de l'enseignement de la direction et de la gestion des organisations da École des Hautes Études Commerciales.

Tradução de Sérgio Rodrigues Costa - Engenheiro Mecânico de Produção pela UFMG, revista por José Luiz Celeste, Professor Assistente do Departamento de Informática e Métodos Quantitativos da EAESP/FGV. 
dustrial. O objetivo desta pesquisa foi fornecer contribuições para o pensamento estratégico do empreendedor e suas ações. Estas contribuições foram elaboradas a partir das ações concretas que as empresas praticam.

\section{METODOLOGIA}

Foi realizada uma pesquisa de campo, no espírito da Grounded Theory ${ }^{1}$, para examinar a maneira como os empreendedores atuavam. Durante os cinco anos de duração da pesquisa (1985-1990), estudou-se um total de 51 pequenos empreendedores (15 da Finlândia, 7 da Suécia, 11 da Escócia, 9 da Suíça e 9 do Canadá) e 8 proprietários de grandes empresas do Canadá.

Os empreendedores bem-sucedidos foram apontados através de opiniões de líderes no campo da iniciativa empresarial, incluindo acadêmicos, funcionários graduados, presidentes de associações empresariais, representantes de entidades governamentais e analistas de negócios. Alguns daqueles empreendedores considerados como bem-sucedidos tiveram que ser excluídos posteriormente, por não preencherem todos os critérios de seleção. Assim, alguns integrantes da amostra inicial foram eliminados por não conseguirem manter a lucratividade ou o crescimento de suas empresas acima de uma certa média ou por não se mostrarem suficientemente inovadores para serem chamados de empreendedores. Entretanto, uma amostra de 15 empresas da Finlândia, de um total de 19, foi mantida; e 11 da Escócia, de um total de 13.

Das 51 pequenas empresas estudadas numa primeira etapa, 34 eram altamente bem-sucedidas, e todos os administradores das grandes empresas haviam alcançado o sucesso. Alguns haviam criado organizações que empregavam milhares de pessoas e que eram líderes em seus setores, no Canadá. Todas as empresas que compuseram a amostra tinham de 50 a 250 empregados e todas, exceto quatro, eram do setor industrial. Estas quatro pertenciam ao setor de serviços. A discriminação dos casos está contida na tabela 1.

Foram realizadas entrevistas semi-estruturadas que duraram, em média, de 3 a 5 horas, e até mais de 10 horas em alguns casos. Foi também utilizada a metodologia soft systems, desenvolvida por Checkland $^{2}$, para mapear os sistemas implícitos de atividade humana dos empreendedores, que explicitam as maneiras como eles agem. Atenção especial foi dada à identificação das definições básicas (root definitions), elemento-chave na abordagem de Checkland. Esses modelos sistêmicos individuais foram então superpostos. Os elementos-chave, comum a todos eles, foram capturados para se chegar ao modelo geral aqui apresentado como um metamodelo empreendedor.

O termo metamodelo é usado aqui na forma exposta por Stafford Beer e John P. Van Gich: "um metamodelo é um modelo com

\begin{tabular}{|c|c|c|c|}
\hline \multicolumn{4}{|c|}{ Tabela 1 Casos estudados } \\
\hline País & $\begin{array}{l}\text { Muito bem-sucedidos } \\
\text { Empreendedores/proprietários } \\
\text { administradores }\end{array}$ & $\begin{array}{l}\text { Proprietários } \\
\text { administradores }\end{array}$ & TOTAL \\
\hline Finlândia & 12 & 03 & 15 \\
\hline Suécia & 05 & 02 & 07 \\
\hline Escócia & 10 & 01 & 11 \\
\hline Suiça & 01 & 08 & 09 \\
\hline Canadá & 06 & 03 & 09 \\
\hline \multirow[t]{2}{*}{$\begin{array}{l}\text { Canadá* } \\
\text { *(Empresas Grandes) }\end{array}$} & 08 & - & 08 \\
\hline & 42 & 17 & 59 \\
\hline
\end{tabular}

1. GLASER, B. G., STRAUSS, A. L. The discovery of grounded theory: strategies for qualitative research. Hawthorne, New York: Aldine Publishing, 1987.

2. CHECKLAND, P. Systems thinking. Systems practice. Chichester: New York, Wiley, 1981. 
3. VAN GIGCH, J. P. Decision making about decision making metamodels and metasystems. Cambridge: Mas and Tunbridge Wells, Kent, Abacus Press, 1987.

4. N.R.: no original, visionary process, ou seja, processo visionário. Como, em português, o termo possui sentido pejorativo. foi conservada a cincunlocução.

5. EDEN C.: JONES, S.; SIMS D.; GUNTON, H. images into models. The subjective world of the policy maker. Futures, 0 . 56-62, Feb. 1979; MACCOBY M. The Leader. New York: Simon and Schuster, 1981; BENNIS, W. Leadership transforms vision into action. Industry Week, p. 54-6, May, 1982; MINTZBERG, $\mathrm{H}$. WATERS \& A. The mind of the strategist(s). In: SRIVASTVA, $S$, et al. The executive mind. São Francisco: Jossey-Bass, p. 58-83; SRIVASTVA, S. Intraduction: common themes in executive thought and action. In: $\quad 0 p$. cit. p. 1-14; GLUCK, F. W. Vision and leadership. Interfaces, $v$. 14, n. 1, p. 10-18, Jan./Feb. 1984; MENDELL, J. S.; GERGUOY, H. G. Anticioatory management or visionary leadership: a debate Management Planning, p. 28-31, Nov./Dec. 1984; BENNIS W: NANUS, B. Leaders. New York: Harper \& Row, 1985; BROWN, I. E. Jr. Sustaining the entrepreneurial vision in cooperative firms". In: RONSTADT, $R$. et al. Frontiers of entrepreneurship research, 1986. Wellesley, Mass.: Babson College, 361-63, 1986; HUNSICKER, J. Q. Vision, leadership and Europes future. The Mckinsey Quartely, p. 22-39, Spring, 1986- LEAVITT. H. J. Corporate Pathfinders. Homowood: III Dow-Jones Irwin, 1986; also New York: Penguin Books, 1987; RICHARDS, D.; ENGEL, $S$. After the vision: suggestions to corporate visionaries and vision champions, 1986. In ADAMS, John D. Transtorming leadership from vision to results. Alexandria, Va.: Miles River Press, p. 199-214, 1986; ROCKEY, E. H. Envisioning new business: how entrepreneurs perceive the benefits of visualization In: RONSTADT, R. Frontiers of entrepreneurship research 1986 . Wellesley, Msaa: Babson Coliege, p. 344-60; SASHKIN M True vision in leadership. Training and Development Journat, May, p. 68-1, 1986; A theory of or- um nivel mais elevado de abstração, que transforma as propriedades dos sistemas de nivel inferior em proposiçōes do modelo de maior nivel de abstraçño".

Os casos finlandeses foram utilizados no desenvolvimento do modelo, enquanto os de outros países foram usados para confirmação de sua funcionalidade e controle de sua validade. Nos casos escoceses, as pessoas diretamente ligadas aos empreendedores foram também entrevistadas: gerentes-gerais, membros da diretoria, representantes das principais instituições financeiras envolvidas, representantes de sindicatos e alguns empregados. Todas as entrevistas foram arquivadas em um computador e analisadas por temas.

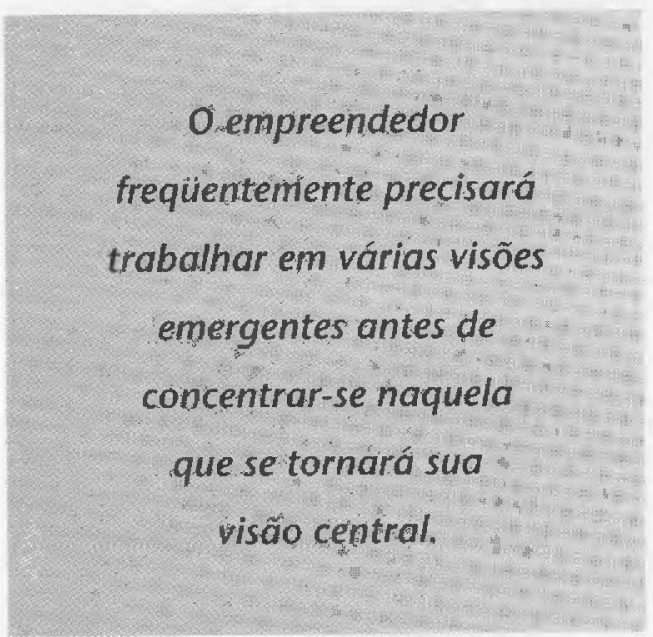

\section{PRINCIPAIS DESCOBERTAS}

As descobertas das pesquisas podem ser distribuídas em duas categorias: de um lado as que aperfeiçoam o conhecimento de um aspecto da realidade estudada, de outro as que aperfeiçoam o modo de pensar e de operar numa área particular. A maioria das pesquisas realizadas é da primeira categoria, mas é com relação à segunda que este trabalho se desenvolveu, visando a apresentar um metamodelo sistêmico do pensamento e da ação dos empreendedores. Esta é a razão pela qual dados estatísticos não foram analisados neste estudo.

Este metamodelo implica o desenvolvimento e a realização de três categorias de visão: emergente, central e complementar. Os empreendedores bem-sucedidos evo- luem de uma categoria a outra, no processo de pensar de acordo com uma visão. ${ }^{4} \mathrm{O}$ principal fator em que se baseia, tanto o desenvolvimento da visão como a realização da mesma, é o sistema de relações do empreendedor. Outros fatores, ainda, contribuem para o desenvolvimento da visão: liderança, energia e as percepções, estas condicionadas pelos valores de cada um. As últimas são apresentadas através do conceito de Weltanschaung.

\section{$O$ conceito de visão}

O fator visão é de extrema importância para a definição das bases dos sistemas identificados. Uns poucos autores haviam voltado sua atenção para esse fator até quando iniciamos esta pesquisa, mas o interesse pelo assunto vem aumentando consideravelmente nos últimos anos. Dentre os mais renomados autores que primeiro escreveram sobre o assunto, incluem-se Jones Sims Eden e Gunton; Maccoby; Bennis; Mintzberg e Waters; Srivastva; Gluck; Mendel e Gerguoy; Bennis e Nanus; Brown; Hunsicker; Leavitt; Richard e Engel; Rockey; Sashkin; Silva e Hickman; dAmboise e Gasse; Isenberg; Morris; Robins e Duncan; Eden; Peters; Carrière; CEGOS; Tregoe, Zimmerman, Smith e Tobia; Westley e Mintzberg. ${ }^{5}$

Visão é definida como uma projeção: uma imagem, projetada no futuro, do lugar que o empreendedor deseja que seu produto venha a ocupar no mercado. É, também, uma imagem do tipo da empresa necessária para alcançar esse objetivo. Em suma, visão refere-se a onde o empreendedor deseja conduzir seu empreendimento.

Poucos dos empreendedores estudados tinham uma visão precisa da posição desejada para seu empreendimento três ou quatro anos mais tarde. Entretanto, os mais bem-sucedidos já pareciam ter imaginado para sua empresa, um ou mais cenários possíveis e, até mesmo, elaborado essas idéias. Primeiramente, estabeleceram as linhas básicas, talvez da mesma forma que alguns líderes políticos identificam o tipo de sociedade que gostariam de criar, baseando-se em seus conceitos sobre os seres humanos e suas relações sociais. Desta forma, a visão parece fornecer ao empreendedor um referencial que o ajuda a chegar aonde deseja ir.

Este referencial parece atrair, estimular 
e motivar as pessoas que trabalham com ele. Sua equipe, isto é, as pessoas que compõem seu sistema de relações dentro da empresa, parece ficar altamente motivada e ansiosa para trabalhar arduamente e assim ajudar a realizar a visão. Nas páginas seguintes, alguns conceitos básicos e a maneira pela qual se integram ao metamodelo serão explicados com base em exemplos mais típicos.

\section{Três categorias de visão}

Foram identificadas três categorias de visão, a saber: a emergente (ou inicial), a central e a complementar. Nossa discussão aqui ficará limitada a essas três categorias, deixando de lado as várias subcategorias contidas em cada uma delas. A maneira como cada categoria interage com as outras é mostrada na figura 1.

\section{Visões emergentes}

As visões emergentes são formadas em torno de idéias e conceitos de produtos e/ou serviços imaginados pelo empreendedor, que, freqüentemente, antes de se lançar a um empreendimento, pondera várias alternativas de produtos ou serviços. De um processo de seleção entre as visões emergentes resulta a escolha de um produto ou um serviço em particular, que se presta como um esqueleto sobre o qual a visão central é constituída. Em outras palavras, esta escolha fornece ao criador da visão um ponto de referência para focalizar suas idéias.

O empreendedor freqüentemente precisará trabalhar em várias visões emergentes antes de concentrar-se naquela que se tornará sua visão central. Bertrand Poudrier, por exemplo, começou ajudando seu pai a consertar lavadoras de roupas em Victoriaville, Quebec. Posteriormente, trabalhou por mais vinte anos com seis de seus irmãos, consertando caminhões, e explorou muitas idéias diferentes antes de estabelecer seu próprio negócio. Já na casa dos quarenta, ele usou sua experiência de mecânico para desenvolver um novo produto, um caminhão com elevador para linhas aéreas, o qual oferecia mais recursos do que os caminhões que ele sempre consertava.

Ao longo de sua vida, um empreendedor deve continuar a avaliar, selecionar e então integrar novas visões emergentes à sua visão central. Parece ser este o caso dos empreendedores-inventores, como Osmo Suovaniemi, fundador da Labsystems, na Finlândia. Ele baseou seu projeto em micropipetas que projetara ainda quando era estagiário. Uma vez instalada a sua empresa, Osmo desenvolveu vários outros produtos (visões emergentes) destinados ao mercado hospitalar. Entretanto, das cinqüenta patentes registradas por ele e por seus sócios-pesquisadores ao longo de dez

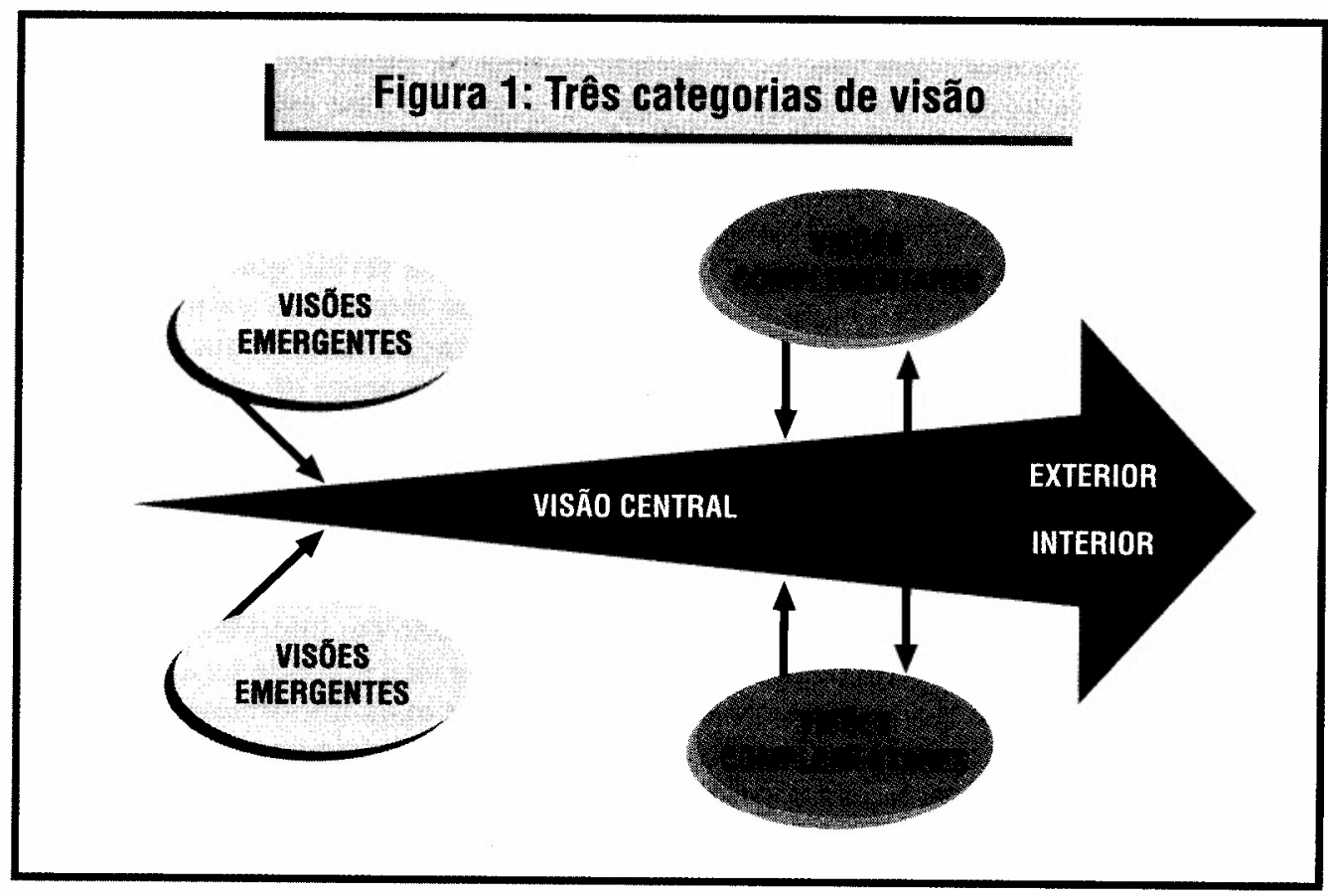

ganizational leadership: vision culture and charisma. Proceedings of symposium on charismatic leadership in management. Montreal: McGill University, 1987; __ The visionary leader. In: CONGER, Jay A. et al. Charismatic leadership: the elusive in organizational effectiveness. San Francisco: JosSey-Bass, p. 122-60, 1988; SILVA, M. A.; HICKMAN, C. R. Creating excellence. New American Library, 1986; D'AMBOISE, G. Gasse, Y. Strategy making in SME: strategic envisioning and planning activities. Québec, $\mathrm{Ca}$ nadá: Faculté des Sciences de l'Administration, 1987. (working paper 87-116); ISENBERG, D. J. The tactics of strategic opportunism. Harvard Business Review, p. 92-7, Mar./Abr. 1987; MORRIS, E. Vision and strategy. The Journal of Business Strategy, v. 8, n. 2, p. 51-8, Fall 1987; ROBBINS, S. R.; DUNCAN, R. B. The formulation and implementation of strategic vision: a tool for change. Seventh strategic management society conference. Boston, Ma, Oct., p. 14-7, 1987; The role of the CEQ

and top management in the creation and implementation of strategic vision. In: HAMBRICK, D. The executive effect: concepts and methods for studying top managers. London, England: JAI Press, p. 205-233, 1987; PETERS, T. Thriving on chaos. New York: Alfred A. Knopf, 1988; CARRIÈRRE, J. B. Strategic vision: an empirical study. FOURTH ANNUAL CONFERENCE OF THE INTERNATIONAL COUNCIL FOR SMALL BUSINESS, Canadá (I.C.S.B.) Windsor, Ontário, Nov.1989; CEGOS. Le Changement par la formation. Paris: Les Editions d' Organization, 1989; TREGOE, B. B. ZIMMERMAN, J. W. R.; TOBIA, P. M. Vision in action. New York: Simon and Schuster, 1989; WESTLEY, F.; MINTZBERG, $H$. Visionary leadership and strategic management. Strategic Management Journal, v. 10, p. 17-32, 1989. 
anos, apenas três linhas de produtos foram colocadas em produção, todas ocupando uma invejável fatia do mercado na Escandinávia e na Europa. Assim, a partir das suas visões emergentes de vários tipos de equipamentos de análises clínicas, Osmo progrediu em direção à visão central focalizada no desenvolvimento daqueles produtos, que são considerados os mais avançados, tecnologicamente, no campo das análises e dos diagnósticos clínicos.

\section{A visão central}

A visão central é, freqüentemente, o resultado de uma única visão emergente, $\mathrm{e}$ às vezes é a combinação de várias visões emergentes. Para empreendedores com visão, ${ }^{6}$ existe uma continuidade entre suas visões emergentes e a central. Exemplo disso é Stafan Preutz, um oculista da Suécia, como o foram seu pai e seu avô. Ainda recém-formado, trabalhou sobre várias visões emergentes, voltadas para o projeto, produção e comercialização de armações de óculos. Logo depois abriu sua própria empresa no norte da Suécia e, além de fabricar uma linha de produtos mais convencionais, ele evoluiu para o projeto e a comercialização de óculos sem armações. Sua empresa, a Polarias, tornou-se desde então líder mundial no ramo. Suas visões emergentes consistiam originalmente de armações de design arrojado, enquanto sua visão central, formada por um gama de produtos, estava mais ligada a um mercado-alvo do que a um único produto.

Heikki Bachmann, da Finlândia, aproveitou-se de seus estudos na universidade, para desenvolver uma visão sobre o que iria fazer com a empresa da família, uma fábrica de cofres com apenas vinte empregados, naquele tempo. Com base em várias visões emergentes, gradualmente começou a reforçar sua visão central, tornando-se um dos primeiros a trabalhar no projeto de cofres e a oferecer opções de cores. Foi ele, também, um dos primeiros donos de pequena empresa, na Finlândia, a exportar seus produtos, no início da década de 60 . A visão não inclui apenas os produtos, mas envolve também o mercado, isto é, o tipo de consumidores para os quais são direcionados. Bachmann teve que instituir várias mudanças organizacionais para conseguir projetar sua vi- são. Certa vez, quando tinha 60 emprega- dos, a companhia foi paralisada por uma greve, e, ao invés de operar com um sindicato hostil, ele decidiu fechá-la. Meses mais tarde, ele a reabriu, lançando as bases de uma nova companhia que se desenvolveria sem a presença de um sindicato. $O$ caso Heikki Bachmann revela os tipos de componentes que formam uma visão central: os interiores e os exteriores. A visão central exterior focaliza o lugar que o empreendedor quer que seus produtos ou serviços ocupem no mercado. A visão central interior focaliza o tipo de organização que ele necessita criar para ser capaz de atingir o seu objetivo.

Os empreendedores de sucesso procuram espaço, aberturas e nichos de mercado. Primeiramente, eles desenvolvem o componente exterior, e o componente interior torna-se, então, uma condição para essa realização; um certo tipo de organização deve ser implantado para permitir à empresa diferenciar-se no mercado. Por exemplo, num período de 20 anos, Heikki Tavela tornou-se líder na Finlândia e um dos líderes na Europa na fabricação e venda de produtos plásticos, especialmente cofres. Tornou-se um experiente homem de visão, pois soube identificar um espaço para seus produtos no mercado. Hoje, beirando os 60, ele é um líder em diferentes ramos de negócio, apesar de ter-se aposentado aos 40 anos. Fixando-se na Espanha desde então, deixou sua empresa, a MK-Tuote, operando sozinha, como um relógio bem ajustado, um mecanismo que ele visualizara. Tinha entendido que precisava de um certo tipo de organização para ser capaz de atuar no mercado que desejava.

Essa pesquisa revela que, quanto mais o componente interior da visão permite a uma organização tomar uma forma que incorpore as inovações do componente exterior, tanto mais bem-sucedido o empreendedor. De fato, à visão central do empreendedor bem-sucedido focaliza a posição que ele quer que os seus produtos ocupem no mercado. Esse fenômeno parece ter aumentado em importância nos últimos anos, e é fácil entendê-lo, à luz do papel, cada vez mais importante, desempenhado pelo marketing nas atividades gerenciais.

Para alguns, o componente mais importante parece ser a visão interior: o tipo de original, ou seja, empreendedores visionários 
organização a ser criada. A expectativa aí implícita é que a implantação do modelo organizacional imaginado levará à ocupação do segmento do mercado visualizado. Muito embora qualquer um deles pareça ser mais importante que o outro, ambos os componentes estão quase sempre presentes na visão central.

Se um dos componentes ou ambos não forem claramente formulados, ou ainda se não forem coerentes, a empresa não será bem-sucedida. Este é, freqüentemente, o caso de empreendedores que dão grande importância à pesquisa e desenvolvimento mas que são incapazes de projetar uma visão externa realista. Outros conseguem definir, de forma realista, as visões externas, mas não são bem-sucedidos na criação da visão interna, ou seja, na formulação de um modelo organizacional fiel à visão externa.

Resumindo, os aspectos característicos da visão central são os seguintes: devem expressar uma visão realista, viável e acreditável do espaço que o empreendedor deseja que seus produtos ocupem no mercado e do tipo de organização necessária para chegar lá.

\section{As visões complementares}

A visão central é apoiada, em seu desenvolvimento, por uma série de visões complementares, enxertadas em seus componentes interiores e exteriores. Uma visão central raramente continuará a se desenvolver além de um certo ponto, se rẫo tiver esse apoio das visões complementares. Neste sentido, essa pesquisa não revelou sequer um único caso contrário.

As visões complementares consistem num conjunto de atividades gerenciais, que precisam ser realizadas, caso se queira o progresso da visão central. O empreendedor se transforma numa espécie de definidor ou ativador de visōes complementares, que lhe permitirem desenvolver os componentes da sua visão central. A habilidade de comunicar é essencial, neste aspecto.

Quanto mais experiência o empreendedor tenha adquirido no seu campo, mais apto estará para definir claramente as visões secundárias que deseja que aconteçam. Gustaf Jonsas, que administra três empresas, incluindo a Inter-Marketing, na Finlândia, é um bom exemplo. Sete de seus
65 empregados trabalham no desenvolvimento de produtos. Este empresário definiu tão bem o que espera de cada um, que agora reclama não haver suficientes empreendedores em sua empresa; e acha ridículo gerenciar uma companhia onde todos se reportam ao diretor. Mesmo assim, ele atinge resultados impressionantes.

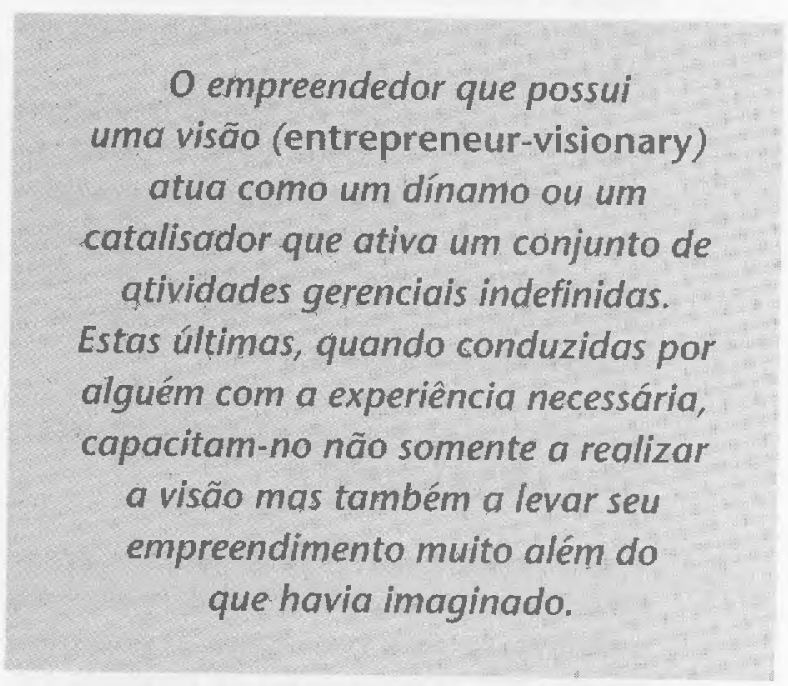

Quanto menos experiência tem o empreendedor, no seu campo, ou quanto mais novo for o campo, mais as visões complementares são definidas por seus subordinados em suas respectivas especialidades. Gio Benedetti chegou à Escócia aos 10 anos de idade, e já no seu tempo de escola trabalhava como garçom num café de seu tio. Aos 19 anos, comprou uma lavanderia especializada em lavagem a seco, mas, ao invés de esperar que os clientes o procurassem, foi de porta em porta oferecendo descontos especiais para aumentar suas vendas. Poucos anos depois, ele já havia montado nove outras lavanderias e adquirido um pequeno shopping-center e alguns imóveis. Foi quando ele encontrou um cliente potencial que queria mandar lavar as luvas industriais de seus empregados. Gio montou uma pequena empresa, a primeira num campo totalmente novo, não apenas para lavar luvas, mas também para reciclá-las: a Industrial Clothing Services. Recrutou pessoal experiente para exercer funçôes-chave na nova empresa, entre pessoas competentes de seu conhecimento. Uma delas se encarregou da organização interna e outra das vendas. Em poucos anos, tornou-se líder no novo setor, com mais de 200 emprega- 
7. FILION, Louis Jacques. The strategy of successful entrepreneurs in small business: vision, relationships and anticipatory learning. University of Lancaster, 1988 (UMI 89119064), (tese de doutorado).

8. Weltanschauung: a palavra se origina do alemão, e o conceito, de há muito, vem sendo usado por estudiosos alemães, como, por exemplo, Max Weber. Norte-americano de origem austríaca, Peter Drucker utiliza-a esporadicamente, assim como o fazem autores britânicos, que têm participado da elaboração de enfoques sistêmicos, como BOULDING, K. E. The Image. Ann Arbour: University of Michigan Press, 1956; CHECHLAND, P. Op. cit. Não existe uma palavra em inglês, que reproduza 0 mesmo sentido, a mais próxima é image. dos e franquias vendidas em quase todos os países europeus. $\mathrm{O}$ empreendedor que possui uma visão (entrepreneur-visionary) atua como um dínamo ou um catalisador que ativa um conjunto de atividades gerenciais indefinidas. Estas últimas, quando conduzidas por alguém com a experiência necessária, capacitam-no não somente a realizar a visão mas também a levar seu empreendimento muito além do que havia imaginado.

As três categorias de visões interagem entre si intensamente. Para evoluir de uma categoria para outra, o empreendedor precisa de um alto nível de articulação pessoal, coerência e tenacidade, todos eles importantes fatores para o sucesso ou o fracasso de sua estratégia.

\section{O PROCESSO DE PENSAR ATRAVÉS DE UMA VISÃO: UM METAMODELO}

O metamodelo do processo de pensar através de uma visão (visionary process) apresentado aqui (ver figura 2) é resultado de uma superposição de modelos extraídos de estudos de doze pequenos empreendedores finlandeses reconhecidamente bem-sucedidos. Esse metamodelo foi, então, testado com 22 pequenas empresas da Suécia, da Escócia, da Suíça e do Canadá, e com 8 proprietários de grandes empresas no Canadá (ver tạbela 1). Alguns desses casos podem ser encontrados em Filion. ${ }^{7}$ Apenas os elementos comuns e mais relevantes dos modelos individuais foram conservados no metamodelo, e muitos elementos específicos foram excluídos quando não reapareciam. Em seguida, ele foi comparado a modelos extraídos de empreendedores menos bem-sucedidos: 17 ao todo. Pelo menos um dos quatro elementos essenciais mostrados não forneceu o suporte necessário para que a visão fosse desenvolvida ou realizada.

\section{O processo de pensar através de uma visão}

O processo de pensar usando uma visão, aqui proposto, incorpora os quatro elementos que sustentam a visão, cada um deles influenciando os demais e viceversa. Um deles, o sistema de relações, desempenha um papel mais importante do que os outros e será discutido mais de- talhadamente logo após a discussão sumária dos outros três.

\section{Weltanschauung 8}

Weltanschauung (W) é o prisma através do qual o indivíduo enxerga o mundo real. Ele inclui valores: é o que é notado como significativo quando a realidade ao redor é filtrada através de valores, atitudes, humor e intenções. O termo está freqüentemente associado a imagens, modelos e outras formas de representação da realidade. Assim como os valores, o Weltanschauung (W) não é fixo, sendo continuamente reformulado, à luz do contexto em que o indivíduo opera ou decide operar. O conceito do " $W$ " é interessante para compreender empreendedores e pequenos empresários. O que é relevante não é o que de fato há no mundo real, e sim o que o empreendedor pensa que há ali. Se um pequeno negócio deve ser visto como um sistema social, construído ao redor do seu proprietário, a identificação de seus Ws ajuda a compreender a cultura resultante (ver figura 2).

Os Weltanschauungen (Ws) constituem a base com a qual se desenvolve o processo de criação da visão do empreendedor. Esse processo consiste, basicamente, em projetar Ws sobre o futuro ou em escolher, no presente, os Ws ou as imagens com que o empreendedor e a sua empresa vão prosseguir no futuro. Evidentemente, um empreendedor não pode decidir facilmente se deseja ser alguma coisa, sem antes saber o que significa ser essa coisa. Portanto, um dos primeiros exercícios no processo de desenvolvimento da visão consiste em descrever os elementos que estão por trás dos seus Ws ou imagens, isto é, por trás da sua maneira de perceber o mundo real. O empreendedor pode fazê-lo procurando entender sua própria história, valores e os modelos resultantes do seu passado familiar, sua experiência profissional, sua educação informal (leitura, viagens, filmes etc.), suas crenças, seu sistema de relações etc.

Os empreendedores estudados parecem ter sido influenciados de maneira especial pelos exemplos fornecidos pelos empreendedores que conheciam. Pierre Lespérance fundou o Grupo Sogides, um empreendimento sediado em Montreal, atuando no campo editorial, na distribui- 
ção de livros e em livrarias. Seu pai imprimia um pequeno jornal e distribuía revistas. Pierre foi criado neste ambiente. Quando seu pai faleceu prematuramente, vítima de um ataque do coração, os negócios eram dirigidos por um holding familiar, Pierre, então com 25 anos, comprou a empresa, e em 20 anos tornou-se um dos maiores editores no Canadá.

Quanto mais cedo o empreendedor começa a trabalhar no campo escolhido, mais parece produzir visões realistas do que ele deseja alcançar. Pierre Lespérance é um bom exemplo disso, uma característica também observada em vários outros empreendedores estudados nesta pesquisa. Eles tiveram que se tornar líderes em campos onde começaram a trabalhar ainda jovens ou onde suas familias já atuavam.

Além da educação e dos exemplos que estão à sua volta, a função que o empreendedor define para si e a sua auto-percepção parecem influenciar seus Ws. Quanto mais jovem ele escolhe o que fazer, mais tempo tem para pensar sobre o que quer tornar-se. Seus W's corresponderão melhor ao papel que ele escolheu para si, para ajudá-lo a concretizar o que visualizou. Isto é verdadeiro especialmente em negócios familiares, onde se decide logo cedo quem tomará a frente dos negócios, dando ao escolhido tempo suficiente para aceitar esse papel e desempenhar-se através dele.
Os sucessores, freqüentemente, introduzirão mudanças na organização, não apenas por terem uma visão diferente, cuja origem está nos diferentes Ws desenvolvidos em contextos diferentes, mas também porque aqueles Ws vão originar diferentes maneiras de pensar e agir. Este é o caso de Jacques e Gérard Vaudax, da Vaudaux \& Vaudaux em Genebra, a terceira geração a conduzir os negócios da família. A fim de tornar suas visões aceitáveis, eles devem explicar os seus Ws, enfatizando as visões para os executivos seniores da empresa. Se a equipe não compreender estes Ws, perderá seu entusiasmo. Quando um empreendimento suíço produz estojos para relógios, e os relógios suíços têm tido boa saída, o panorama é agradável. Mas ao considerar o momento em que japoneses estão invadindo o mercado de relógios, será preciso redirecionar a visão e então diversificar. É necessário envolver os executivos nesse processo. Uma compreensão recíproca dos Ws, portanto, torna-se um fator vital não somente no autoconhecimento, mas também na compreensão do progresso da visão dos empreendedores.

\section{Energia}

A energia é o tempo alocado em atividades profissionais e a intensidade com

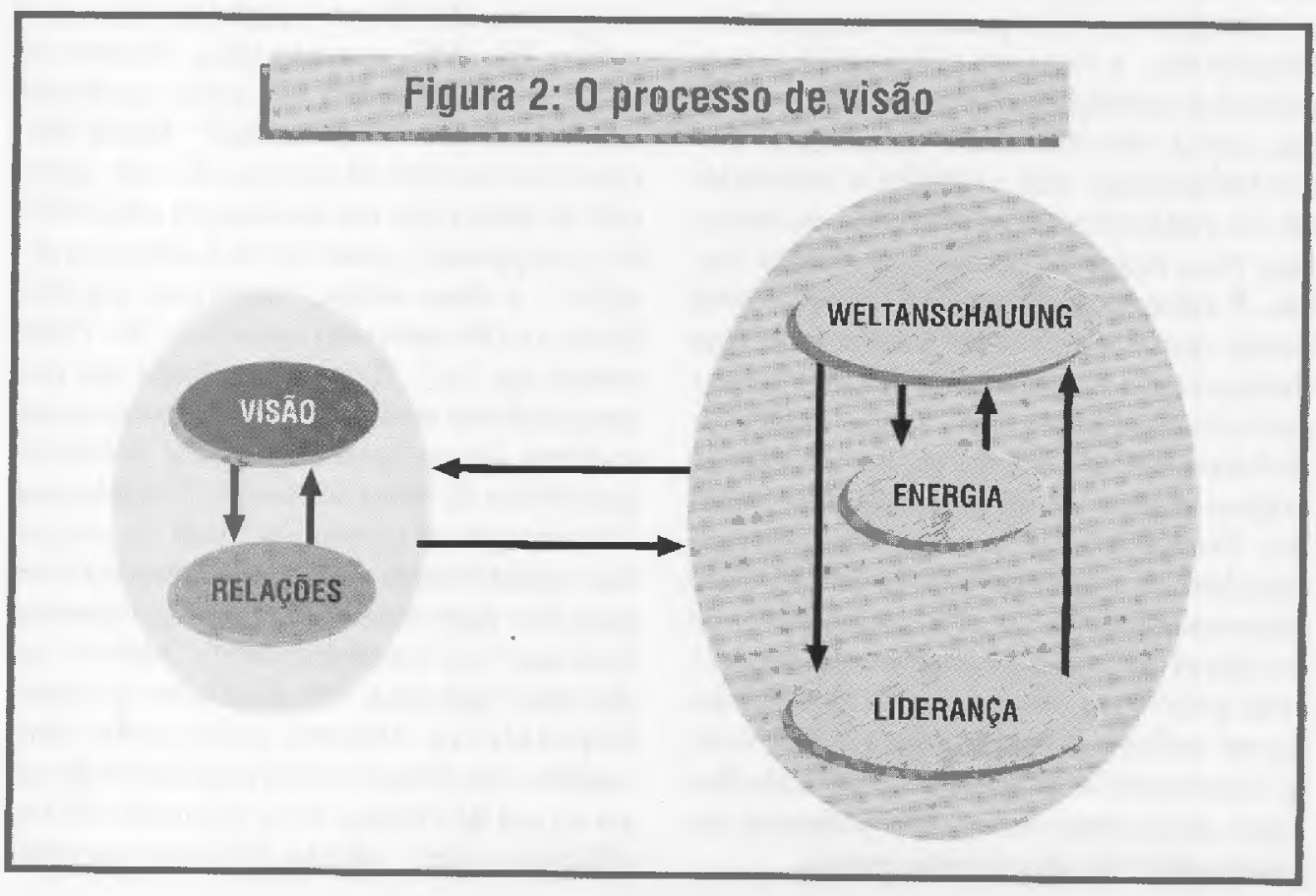


que elas são executadas. Os Ws ou valores do empreendedor irão influenciar na definição do que ele vai dispor para investir em sua vida profissional. A energia dispendida pode conferir mais liderança, pode levar um empreendedor a dedicar mais tempo para criar e preservar relacionamentos ou articular uma visão, e todas essas atividades reunidas podem resultar no ajuste dos Ws. Ademais, a energia empregada para assumir a liderança deverá retornar ao empreendedor, pelo menos em parte, de uma forma ou de outra, e, às vezes, em quantidade maior do que ele investiu.

A energia dispendida na criação e na manutenção de relacionamentos paga dividendos, porque um empreendedor que esteja bem situado num sistema de relações lucrará por um fluxo constante de informações. Isto permitir-lhe-á reajustamentos contínuos. Outrossim, quanto mais tempo e energia ele dispender no desenvolvimento da sua visão, mais lucros receberá, porque as diretrizes que vier a desenvolver vão gerar motivação e energia naqueles que o cercam.

Todos os empreendedores estudados nesta pesquisa dedicaram grande parte do seu tempo ao trabalho. Entretanto, alguns empreendedores que trabalham arduamente não parecem ter êxito. Tal fato leva a sugerir que não há uma relação direta entre o número de horas trabalhadas e o sucesso obtido por um empresário. Entretanto, a energia permanece como uma das condições para o sucesso; o termo inclui não somente o número de horas trabalhadas mas também a intensidade ou conhecimento dedicados ao trabalho. Não basta trabalhar por longas horas. É necessário trabalhar intensamente desde que o que estiver sendo feito seja interiorizado e usado para auxiliar no desenvolvimento da visão. Vários empreendedores têm investido uma quantidade extraordinária de energia em seu trabalho. Pekka Anttila, por exemplo, é proprietário da Lapponia em Helsiniki; uma empresa joalheira de alta classe, com um invejável reconhecimento internacional. Seus pais eram fazendeiros e ele foi criado em ambiente rural onde, ainda jovem, se acostumou a longas horas de trabalho. Aqui mais uma vez os Ws parecem desempenhar um importante papel.

\section{Liderança}

A liderança resulta dos $\mathrm{Ws}$, da energia e dos relacionamentos, mas, reciprocamente, exerce influência sobre os três elementos. Sua importância para o desenvolvimento da visão decorre do seu impacto sobre o nível da visão e da extensão daquilo que o empreendedor pretende realizar. A liderança afeta seu desejo de realizar, e isto, por sua vez, determina, em grande parte, o alcance de sua visão. $\mathrm{Na}$ realidade, é muito pouco provável que um líder supere sua própria visão, apesar de ser ela parte de um processo contínuo, como ocorre com os Ws, passíveis de reformulações periódicas. A esta altura, podemos até mesmo questionar a origem da liderança: o que é que transforma uma pessoa em líder? Muita coisa pode ser mencionada, mas, no que diz respeito aos empreendedores, a liderança parece ir surgindo numa evolução gradual, que requer a aquisição de uma habilidade particular, num setor particular de atividade. A habilidade para desenvolver uma visão parece conferir liderança, e esta, para o empreendedor,depende do desenvolvimento da visão.

David Murray, por exemplo, começou a vender ferro velho quando saiu da escola secundária, aos 16 anos. Aos 24 ele iniciou seu próprio negócio e naquele ano perdeu as duas pernas num acidente automobilístico. Apesar disto ele criou um conglomerado internacional atuando em 7 países. Em 1985, quando tinha 32 anos de idade, eu perguntei a ele como explicaria seu sucesso. Sua resposta foi: "Minha liderança dentro e fora da empresa. Eu sou conhecido no ramo como um dos maiores comerciantes, $e$ as pessoas gostam de vir a mim com desafios.", e disse ainda: "Mostre-me um problema e eu the mostrarei como sair dele. Tenho renome por isso". É isto que o torna um dos fornecedores mais procurados pelos construtores de equipamentos para indústria petrolífera de todo o mundo. É sabido que ele é imbatível quando se trata de encontrar rapidamente uma peça sobressalente para um item defeituoso ou não existente. Para ele, "ser o número um", "vencer" no que quer que faça, tem sido fator de suma importância. Mesmo possuindo uma mansão em Jersey e uma residência de luxo no sul da França, ter a reputação de excêntrico e uma coleção de carros esporti- 
vos italianos, sendo dono do Hotel Cordonbleu em Edinburgo, dificilmente tira férias. Além de gerenciar todos os seus empreendimentos, ainda gasta $80 \%$ de seu tempo fazendo vendas.

Sua necessidade de liderança o teria induzido ao desenvolvimento da visão ou sua visão o teria transformado num líder? Segundo o próprio David Murray, sua necessidade de vencer no início o levou a adquirir uma certa quantidade de liderança. Mas, tendo já alcançado seu objetivo, ele observa uma meta importante para a realização da sua visão: estabelecer a Murray Inc. em "todos os lugares, como os tentáculos de um polvo". Sua visăo o dotou com liderança.

\section{Relações}

O sistema de relações, aparentemente, é o fator mais decisivo para explicar a evolução da visão. A família, sistema básico de relações de um empreendedor, certamente moldará os tipos de visão inicial que possa ter. Depois, as relações que ele estabelece, com a finalidade de desenvolver suas visões complementares, serão de importância fundamental para o desenvolvimento de sua visão central. Por outro lado, quanto mais articulada for sua visão, tanto mais importante será o papel por ela desempenhado na escolha dos critérios para o estabelecimento de um sistema de relações. O velho ditado "dize-me com quem andas e eu te direi quem és" não poderia ser mais verdadeiro do que aqui. De um ponto de vista baseado na visão, o ditado poderá até mesmo ser mudado para "dize-me quem tu queres que seja teu amigo e eu te direi quem tu serás".

Jean-Jacques Rousseau definiu o homem como um produto social. Esta definição é bastante relevante quanto aos empreendedores estudados. Eles são originalmente produtos dos sistemas de relações da família, que depois desenvolvem uma rede de relacionamentos empresariais, de modo que as pessoas nela envolvidas se tornam produtos sociais de que o empreendedor precisa, à medida que venham realizar sua visão. Tendo ele tomado a forma do papel que definira para si mesmo, o empreendedor espera o mesmo dos que trabalham com ele, e até mesmo os condiciona para assim o fazerem. Quase inevitavelmente uma ou duas mulheres foram observadas trabalhando junto a empreendedores bem-sucedidos, apoiandoos incondicionalmente, absorvendo a cultura de seus empregadores e trabalhando de forma leal e intensa em seus projetos. De fato, os empreendedores estudados confirmaram que seus sistemas de relações internas foram mais importantes que os sistemas externos.

Muitos destes empreendedores levam em consideração este aspecto ao conduzir seus empreendimentos. Para eles o recru-

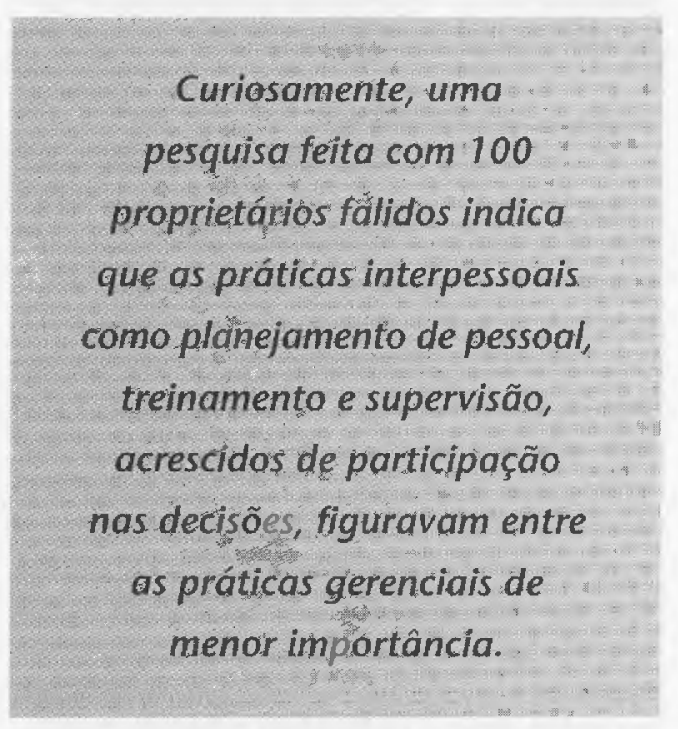

tamento de pessoal vein a ser um aspecto de especial importância. Bernard Vonlanthen, da Suíça, por exemplo, montou um empreendimento no campo da limpeza industrial e comercial. Em poucos anos ele já dominava uma parte respeitável do mercado suiço, num ramo de fácil ingresso. Uma razão para o seu sucesso é a seleção de pessoal, particularmente os executivos. Os futuros colegas dos novos membros da equipe são envolvidos nesse processo. A partir da segunda ou terceira entrevista, os candidatos selecionados são colocados em situaçōes onde eles têm um problema real para resolver. Somente após sete ou oito encontros com os candidatos, é que as pessoas envolvidas no processo farão suas escolhas. O processo tem uma característica de socialização com efeitos a longo prazo, que também tornam a integração a curto prazo, muito mais fácil. A energia gasta nas relaçōes internas aparentemente explica, na maioria dos casos, o sucesso dos empreendedores. $\mathrm{Cu}$ riosamente, uma pesquisa feita com 100 
proprietários falidos indica que as práticas interpessoais como planejamento de pessoal, treinamento e supervisão, acrescidos de participação nas decisões, figuravam entre as práticas gerenciais de menor importância. ${ }^{9} \mathrm{O}$ contrário pode ser observado naqueles que vencem.

\section{IMPLICAÇÕES E CONCLUSÃO}

As implicaçōes afetam as três áreas da atividade empreendedora: a ação empreendedora, a pesquisa e a educação para atividades empreendedoras.

\section{Ação empreendedora}

O processo de pensar de acordo com uma visão fornece estrutura para a reflexão e a ação. Fornece também ao empreendedor um meio de integrar toda a equipe naquilo em que estiver trabalhando. Uma das conclusões que pode ser extraída deste enfoque diz respeito ao quadro cultural que um empreendedor pode criar para si mesmo. O pensar em termos de uma visão dota o empreendedor com um esquema de aprendizado capaz de Ihe dar uma estrutura de referência que o auxilie para melhor articular seu desenvolvimento. Primeiramente, esse processo exige que o indivíduo adquira habilidades não apcnas para analisar, mas também para imaginar e se comunicar, de maneira que possa tornar-se igualmente apto a ouvir e a falar. Não deve ser apenas apto para ouvir, mas deve realmente desejar fazê-lo, uma vez que a visão em função da qual estiver pensando oferecerá um ponto de referência, ao redor do qual, o empreendedor, deverá assimilar informações. O mesmo pode ser dito quanto ao ato de falar: deve estar interessado em dizer o que pensa, pois deseja que seu sistema de relações reaja e se envolva, além de o estimular e apoiar em seu desenvolvimento. Aqui, ele deixa de ser um simples empreendedor construindo um empreendimento: passa a ser um líder que guia toda uma equipe em direção à meta; um líder que cria uma cultura de aprendizado para si mesmo, transmissível às pessoas que se encontram ao seu derredor. Eventualmente, será capaz de envolvê-las numa organizaçăo de aprendizado. De fato, o gerenciamento de pequenas empresas pode ser visto como fortemente focalizado no gerenciamento da visão, que fornece um padrão de reflexão, essencial para a eficácia das tarefas gerenciais, as quais, em contrapartida, devem ser exploradas para que as ações concretas ocorram. A tabela 2 mostra algumas das vantagens obtidas com o desenvolvimento de uma visão.

Tornar-se um pensador com visão, a visionary, implica ser alguém capaz de atingir o equilíbrio entre o fazer e o sonhar. Delegar o sonho que leva a uma visão é difícil, mas deve-se delegar o fazer aquilo que se tiver sonhado. Caso realmente se deseje continuar a sonhar. A formação de um sistema de relações é um elemento-
9. LALONDE, C.; D'AMBOISE, G. Le propriétaire-dirigeant failli: les étéments dun profil. Revue de gestion des petites et moyennes organisations, PMO, vol. 1, n. 4, p. 5-11, 1985.

\section{Tabela 2: Vantagens resultantes da visão}

- Fornece tanto uma orientação quanto uma base para a reflexão e a prática de atividades empreendedoras.

- Permite a unificação de ações e atividades em torno de uma idéia central

- Encoraja o empreendedor a articular visōes realistas, atraentes e dignas de crédito, sobre os objetivos para os quais o empreendimento está voltado.

- Apresenta uma estimulante estrutura básica ao redor da qual o grupo social que compõe a organização pode se unir.

- Induz o empreendédor a canalizar recursos em uma direção ủnica. Eventualmente, a visão poderá materializar-se no formato de missão e de objetivos a serem atingidos. 
chave nesse ponto. Muito se tem dito sobre sua importância. Os dados dessa pesquisa mostram que não é o sistema de relações em si mesmo que explica o sucesso de um empreededor, e sim um sistema de relações construído de modo a dar suporte para a realização da visão.

\section{Educação e treinamento para a atividade empreendedora}

Os elementos essenciais parecem ser o desenvolvimento da imaginação e da criatividade, bem como a habilidade de canalizar energia para os objetivos que o empreendedor quer atingir. $\mathrm{O}$ treinamento empresarial para a atividade empreendedora deve capacitar o empreendedor para imaginar e identificar visōes. Isto significa que há uma diferença entre o treinamento para o empreendedor e o treinamento gerencial, enfatizando-se, no segundo caso, as "habilidades para sonhos realistas", mais do que as habilidades analíticas. O empreendedor necessita, ainda, de habilidades para se comunicar e estabelecer relações interpessoais. A educação para o empreendedor deve auxiliar o indivíduo, no seu desenvolvimento, pelo reforço de suas características diferenciadas. Em certo sentido, isto se assemelha à educação para liderança, principalmente por dar apoio, ao invés de pressionar até se obter a conformidade. Deve ser pró-ativa e não estar centrada em um único método. Deve apresentar aos empreendedores em potencial formas para definir visōes e maneiras de projetar os sistemas de relaçōes e de aprendizado, necessários para levar as visöes adiante.

\section{Pesquisa sobre a atividade} empreendedora

Alguns enfoques metodológicos inovadores são necessários no campo da atividade empreendedora. Quando se está trabalhando sobre o referencial do pensamento, como neste caso, cabe ao pesqui- sador estabelecer uma relação entre o assunto pesquisado e o tipo de metodologia necessária para agrupar e então analisar os dados. As vezes, como nesse caso, é necessário criar uma metodologia para se chegar aos objetivos da pesquisa.

O metamodelo aqui proposto é apenas um, entre vários outros possíveis, que incorpora os principais elementos de modelos individuais de empreendedores estudados nessa pesquisa. Parece ter sido

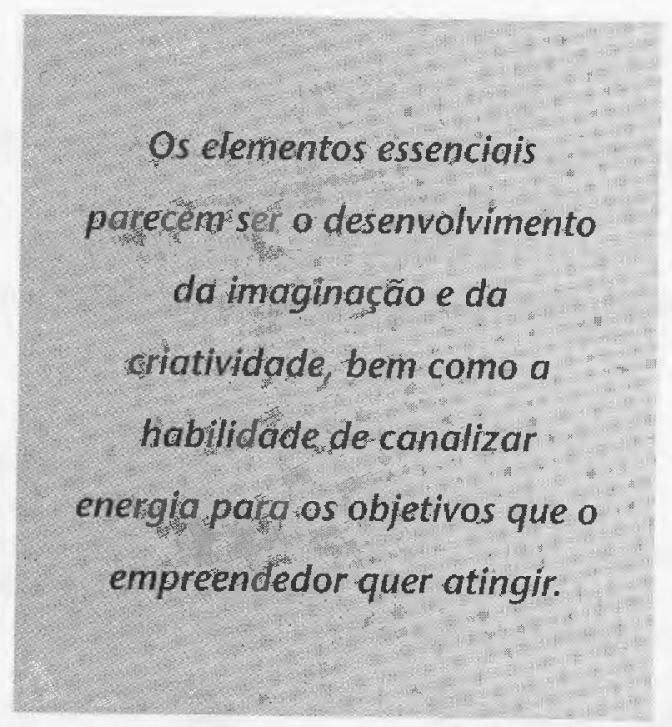

este o denominador comum, mais acessível. Uma vez compreendido, a próxima questão é: como poderíamos utilizar este metamodelo para desenvolver uma visão que seja coerente? Feito isto, como poderia ser absorvido dentro de uma organização, então, ser compartilhado por ela? Tais questōes nos fornecem assuntos para pesquisas futuras.

* Artigo publicado originalmente sob o título Vision and relations: elements for an entrepreneurial metamodel, International Small Business Journal, v. 9, n. 2, Jan.Mar. 1991, Paris, França; e, em português, na RAE - Revista de Administração de Empresas, sob o titulo: 0 planejamento do seu sistema de aprendizagem empresarial: identifique uma visão e avalie o seu sistema de relaçōes, v. $31, \pi .3$, jul./set. 1991, São Paulo: SP.

PALAVRAS-CHAVE: Weltanschauung, treinamento de empreendedores, desenvolvimento de visões, sistema de relações.

KEY WORDS: Weltanshauung, entrepreneurs training, vision development, visionary process, relationship system. 